\title{
Prabin Bikram Thapa, Dhiresh Kumar Maharjan: Pancreas and Hepatobiliary Surgery
}

\author{
Jaypee Brothers Medical Publishers (P) Ltd., 2018
}

\section{Khandelwal ${ }^{1}$}

Published online: 27 July 2018

(C) Association of Surgeons of India 2018

It is a privilege to write a review for a book on "Pancreas and Hepatobiliary Surgery" nicely edited by Dr. Prabin B. Thapa and Dr. Dhiresh K. Maharjan. The chapters and authors have been selected by editors very carefully.

The book provides information about many updated aspects of HPB Surgery. Three chapters describe how to deal pacreaticoduodenectomy in different or difficult situations; like Superior Mesenteric Artery first approach, laparoscopic approach, and vascular resection. It also has chapters on pancreatic necrosectomy, on how to manage pancreatic remnant, and on distal pancreatectomy with en bloc coeliac axis resection.

Other five chapters deal with difficult issues in liver, gallbladder, and bile duct surgery. HPB diseases are very common in this part of word, including Nepal, the country of editors.
Each surgeon needs to know latest about gallbladder cancer (GBC) and hepatocellular carcinoma (HCC). Chapters in the book include operations for HCC and GBC, techniques for managing biliovascular injuries, and also for hilar blocks of the bile duct.

High-quality technical details have been contributed by senior and experienced authors not only from India but also from Japan and Norway. Chosen topics have been dealt in a very clear manner by the authors.

I hope this book will be of immense help to young surgeons learning complex HPB surgery. The book is published in 2018, contains 130 pages only, and is valuable for updating knowledge and for practical technical tips in "Pancreatic and Hepatobiliary Surgery."
C. Khandelwal

khandelwal3250@gmail.com

1 Gastroenterology \& Oncology, Paras HMRI Hospital, Patna, India 